FACTA UNIVERSITATIS

Series: Linguistics and Literature Vol. 16, Nº 1, 2018, pp. 39-64

https://doi.org/10.22190/FULL1801039F

Original Scientific Paper

\title{
TESTING THE PSYCHOLOGICAL REALITY OF PARALLEL STRUCTURE WITH SERBIAN EFL STUDENTS: A CASE STUDY OF "NOT ONLY ... BUT ALSO"
}

\author{
UDC 811.111'367.634:159.9 \\ $811.111^{\prime} 243: 159.9$
}

\author{
Vladimir Figar \\ University of Niš, Faculty of Philosophy, English Department \\ University of Niš, Center for Cognitive Sciences
}

\begin{abstract}
The paper aims to explore the cognitive status of the correlative conjunction 'not only ... but also' on a sample of advanced Serbian EFL students. The experiment is based on grammaticality judgments, and it utilizes a reaction time $(R T)$ study, coupled with the moving screens paradigm. Stimuli (sentences) have been constructed based on the most frequent errors identified in students' exams. Sentences containing errors related to faulty parallelism are presented word-by-word, with a mask, using the Open Sesame software. Increased RTs are understood as correlates of processing difficulties, and in addition to $R T s$, response accuracy was also recorded. The results show that in the majority of cases a lag in RT occurred precisely in the error position, and such delays were directly connected to sudden drops in the number of accurate responses.
\end{abstract}

Key words: correlative conjunctions, grammaticality judgments, reactions times (RTs), psycholinguistics, Open Sesame, EFL

\section{INTRODUCTION}

The issue of psychological reality of grammatical structure is one of great import not only for understanding the cognitive scaffolding that supports language, but also for validating and increasing the levels of explanatory validity of individual theoretical frameworks. One common denominator that can be identified among scholars from various traditions is the idea of the existence of abstract patterns that can be used

Submitted February 17 2018, accepted for publication April 42018

Corresponding author: Vladimir Figar

University of Niš, Faculty of Philosophy, English Department

University of Niš, Center for Cognitive Sciences

E-mail: vladimir.figar.81@gmail.com 
recursively and productively (e.g. Chomsky 2002[1957]; 1965; Langacker 1986; 1987; Jackendoff 1994). Cognitive grammar, for example, proposes that there are abstract schemas (e.g. Langacker 1986; 1987; Kay and Fillmore 1999) which facilitate linguistic creativity and enable language users to construct a potentially infinite number of novel utterances. Building on these ideas the present paper will try to explore the actual cognitive status of the grammatical pattern of parallel structure (i.e. the structure of coordination) by investigating the case of the English correlative conjunction 'not only ... but also' on the sample of Serbian advanced EFL students. The experiment is based on a reaction time (RT) study, where increased RTs will be understood as correlates of processing difficulties associated with the violation of the abstract grammatical pattern, which should in turn attest to the psychological reality of parallel structure.

The paper is organized as follows. After the introduction, the second section will (i) firstly give an overview of the main elements of the theoretical framework which incorporates the structural and cognitivist interpretation of the structure of coordination, as well as the psychological reality of patterns and expectancies associated with it; and (ii) secondly, it will provide a brief overview of the relevant research in psycholinguistics. The third section will describe the sample, stimuli, and procedures used in the experiment. The fourth section will present the main results obtained from the analysis, while in the sixth section we will discuss the obtained results and their implications. The final section will offer the main conclusions and suggestions for future research.

\section{THEORETICAL FRAMEWORK AND PREVIOUS RESEARCH}

\subsection{The structure of coordination}

The structure of coordination entails the joining of parts of a sentence that are grammatically equivalent, i.e. parts that have the same syntactic structure and function (Quirk et al. 1985: 918-919). These 'equivalent' elements can include individual words, various types of phrases, dependent clauses, or complete sentences (Pollock 1982: 46-48). Quirk et al. (1985: 918) also distinguish between syndectic and asyndectic coordination, where the former is explicitly marked by coordinating conjunctions, while in the latter case the explicit markers are missing. Prototypical coordinating conjunctions include and, or, and but (Greenbaum and Quirk 1990: 263).

A special case of coordinating conjunctions includes correlative or paired conjunctions ${ }^{1}$ which consist of two elements (Greenbaum and Nelson 2002). By definition, they also exclusively connect elements of equal grammatical status (Quirk et al. 1985: 940); however, unlike coordinating conjunctions which can be used to connect multiple elements, correlative conjunctions cannot be used when there are more than two elements (Quirk et al. 1985: 939). In addition, correlative conjunctions emphasize the meaning of the 'original' coordinating conjunction based on which they are typically expanded (Biber et al. 1999: 80). Apart from being used for rhetorical purposes of highlighting certain pieces of information introduced into the discourse, correlative conjunctions also have a clear grammatical function reflected in the abstract pattern of parallel structure. Some typical correlative conjunctions include paired elements like the following: not only ... but also, both ... and, either ... or, neither ... nor, etc.

\footnotetext{
${ }^{1}$ Note that Biber et al. (1999: 80) refer to this group of conjunctions as correlative coordinators.
} 


\subsection{Patterns and expectancies}

Langacker (1986: 1) proposes that "language is neither self-contained nor describable without essential reference to cognitive processing." Furthermore, grammar does not constitute a separate independent, autonomous module, but rather goes necessarily hand in hand with meaning and the overall conceptual structure of language which is understood as primary (Langacker 1986; 1987). In fact, in this framework meaning construction is viewed as conceptualization and "any facet of our knowledge of an entity is capable in principle of playing a role in determining the linguistic behavior of an expression that designates it" (Langacker 1986: 6). Grammar "is described by a structured inventory of 'grammatical constructions', each of which specifies the relation between two or more 'component' structures and the 'composite' structure resulting from their integration" (Langacker 2006: 52-53). This again warrants the conclusion that our understanding of various linguistic structures is largely conditioned by our encyclopedic knowledge, context, and various schemas against which we cross-reference the ongoing discourse. Discrepancies in relation to the entrenched schemas and background knowledge structures can in turn lead to difficulties in processing, since this implies a violation of expectancies.

Another important element in Langacker's $(1986$; 1987) framework is the figure-ground distinction in scene construal, where the use of various grammatical constructions enables the speaker to impose a particular profile on the given scene, i.e. to "select a particular image to structure the conceived situation for communicative purposes" (Langacker 1986: 13). Let us consider in this sense the case of the correlative conjunction 'not only ... but also', which will be investigated in more detail in the main experiment below.

As outlined by Biber et al. (1999), correlative conjunctions typically stress the meaning of the initial coordinating conjunction. In this particular case, not only ... but also can be seen as an 'extension' of simple addition by the coordinator and, whose "essential import consists in mentally juxtaposing coequal elements" (Langacker 2008: 410). In effect, the coordinated elements are "conceived together, in a single attention frame" (Langacker 2008: 409). On the other hand, by using a correlative conjunction the speaker imposes a particular construal where he both signals the juxtaposition of two elements, and singles them out as more salient (for current communicative purposes) than the other elements from the respective categories they have been picked out from. In other words, he foregrounds them in relation to the category base. Compare the following two sentences, for example:

1) Jane would like to go to France and to Italy.

2) Jane would like to go not only to France but also to Italy.

In the first sentence there is a simple coordination between two prepositional phrases, in which the two countries are singled out as important. In other words, France and Italy have been profiled as the figure in relation to the ground constituted by the category COUNTRY OF THE WORLD. In the second sentence, the profiling is further 'amplified' through the introduction of the correlative conjunction not only ... but also, which not only connects, but also explicitly stresses the two coordinated prepositional phrases, thereby emphasizing the rhetorical content of the message.

Now consider the following sentence which illustrates faulty parallelism ${ }^{2}$ :

\footnotetext{
${ }^{2}$ In the sense of Lester (2008).
} 
1) ? Jane would like to go not only to France but also Italy.

In light of cognitive grammar, the interpretation of the sentence will require a complex interaction of at least the following elements: background knowledge, general cognitive capacities, semantic knowledge, and grammatical constructions. In that sense, crossreferencing the structure of the sentence against the generalized entrenched schematic template will uncover a violation of expectancy owing to faulty parallelism between the prepositional phrase (to France) and the noun phrase (Italy). This suggests that the violation of the grammatical pattern should be directly connected to the process of meaning construction (i.e. conceptualization), which should in turn cause a lag in processing. Consequently, such delays in processing are expected to provide correlational support for the psychological and cognitive reality of generalized entrenched grammatical patterns.

\subsection{Previous psycholinguistic research}

Kong et al. (2016) employed an online grammaticality judgment task in order to investigate the psychological reality of discontinuous Chinese correlative conjunctions. The researchers' goal was to investigate how the combination frequency of conjunctions affects their processing. Namely, they hypothesized that: (i) if conjunctions were processed online, combination frequency would not affect processing time, and (ii) if combination frequency affected processing times, it would indicate that correlative conjunctions are represented holistically in the mental lexicon.

The study was conducted at Peking University in Beijing, and the experimental stimuli included 4 groups of conjunction combinations, with 24 combinations in each group. The first experimental group was given grammatical correlative conjunctions with high combination frequency; the second group was given grammatical correlative conjunctions with low combination frequency; the third and the fourth group were given random combinations of conjunctions, one with high and the other with low combination frequency. Experimental subjects were asked to assess whether a given pair of conjunctions was a correct correlative conjunction that can indeed connect two elements into a complex sentence.

The analysis of RTs showed shorter RTs for conjunctions with high combination frequency compared to the ones with low combination frequency. Additionally, RTs for grammatical correlative conjunctions were also shorter compared to RTs in the condition with random combinations. Furthermore, RTs "for grammatical conjunctions with high frequency were shorter compared to grammatical conjunctions with low frequency" (Kong et al. 2016: 10). With random combinations of conjunctions, on the other hand, the effect of frequency did not reach significance. The analysis of accuracy of participants' responses showed a significant difference in favor of high frequency grammatical conjunctions compared to the condition with low frequency conjunctions. However, in the condition with random combinations, "accuracy for high frequency combinations was significantly lower compared to accuracy for low frequency combinations" (Kong et al. 2016: 10).

Based on the obtained results, the researchers concluded that "the different patterns of combination frequency effects indicated that correlative conjunctions are psychologically real, but random conjunction combinations are not [and that] the findings are consistent with existing studies on multi-word units" (Kong et al. 2016: 11). Additionally, owing to the holistic representation of Chinese correlative conjunctions in the mental lexicon (in the case of grammatical conjunctions), participants were able to access them very quickly, without additional processing efforts. Random combinations of conjunctions did 
not show a holistic representation in the mental lexicon. Finally, Kong et al. (2016: 12) concluded "that Chinese correlative conjunctions, but not random conjunction combinations, can be represented holistically in the mental lexicon, in addition to their individual word representations," and they attributed such findings to the frequency and grammatical function of correlative conjunctions.

Frazier et al. (1984) investigated the role of parallel structure in sentence comprehension, building on their initial observation that "the preference for parallel structure influences the actual parsing of sentences" (ibid.: 422). The authors also noted that the phenomenon of parallel structure remained largely under-investigated in the context of psycholinguistic research and, consequently, it is unclear which specific elements of mental representation facilitate parallelism.

The experiment included 60 sentences where in some cases the coordinated parallel forms contained the same constructions, while in other cases they did not. Sentences were presented to participants on a computer screen, segment-by-segment. After the participant had read the first segment, he was instructed to press the button in order for the next segment to appear. The second segment was then followed by a question about the sentence. The researchers recorded reading times for each segment, question-answering time, and accuracy.

The obtained results showed a significant effect of parallelism for each of the tested construction types. Namely, participants consistently read the second segment of the sentence faster when it was parallel in structure to the first segment, than when the structures of the two segments were not parallel. One explanation for such findings could be that "when a person has just completed constructing a representation of part of a sentence, fewer cognitive demands will be made by constructing and storing the representation of the remaining part of the sentence to the extent that the representations share common features" (Frazier et al. 1984: 426). In other words, the first segment of a sentence might be used to prime the experimental subject for the subsequent content. Consequently, if the two coordinated grammatical constructions are parallel, processing time is reduced, which is in line with the results obtained in the experiment. Otherwise, if the segments are not parallel, the expectancy afforded by the priming effect is violated, which in turn causes a lag in RTs. Similar effects of syntactic priming by certain grammatical constructions have also been investigated and confirmed by Branigan et al. (1995).

\section{PRESENT RESEARCH}

The main aim of the present research is to test the psychological reality of the English correlative conjunction not only ... but also with advanced Serbian EFL students by investigating the participants' ability to identify faulty parallelism using a 'moving screen paradigm' (e.g. Just et al. 1982). To that end, the paper will attempt to provide answers to the following research questions:

i. Does faulty parallelism cause a lag in RTs?

ii. Does this expected lag in RTs occur precisely in the 'error-position' or is there a delay?

iii. Do the expected changes in RTs for faulty parallelism have any effect on the accuracy of participants' grammaticality judgments? 


\subsection{Sample, stimuli, and procedure}

The study included 26 third-year advanced EFL students from the English Department, Faculty of Philosophy, University of Niš. There were 19 female and 7 male students, with the average age of $\mathrm{M}=21.88, \mathrm{SD}=0.91$. All participants had successfully passed their Contemporary English Language 3 exam a year before the study took place.

Table 1 Stimuli used in the main experiment

\begin{tabular}{|c|c|}
\hline Sentence No. & Sentence - main experiment \\
\hline 1 & Jack not only likes cookies but also ${ }^{*}$ chocolate. \\
\hline 2 & Sam likes not only reading books but also * he likes watching movies. \\
\hline 3 & Sarah not only enjoys skiing but also enjoys * to go to the seaside. \\
\hline 4 & Peter wants to go not only swimming but also * to ride his bicycle. \\
\hline 5 & Jane would like to go not only to France but also *Italy. \\
\hline 6 & Not only would Bob like to visit France but also * Spain. \\
\hline 7 & Not only is the car easy to drive but also *traveling comfortably. \\
\hline 8 & Jack not only plays the guitar but also *drums. \\
\hline 9 & Not only does Bill play the saxophone but also *the trumpet. \\
\hline 10 & Bill would like to campaign not only for the governor but also *the senator. \\
\hline 11 & The new Volvo is not only easy to drive but also *a great sound system. \\
\hline 12 & Bill and Sarah are going not only to the cinema but also * the theater. \\
\hline 13 & Peter enjoys not only hiking but also *he enjoys swimming. \\
\hline 14 & Not only is the house spacious but also * a large swimming pool. \\
\hline 15 & Not only $\overline{\text { is Sarah beautiful but also *intelligent. }}$ \\
\hline 16 & Not only $\overline{\text { does Paul enjoy sailing but also *paragliding. }}$ \\
\hline 17 & Not only does Sarah like reading but also * to go to the cinema. \\
\hline
\end{tabular}

Sentences used as stimuli in the experiment were constructed based on the course materials for Contemporary English Language 3, taught at the English Department, Faculty of Philosophy, University of Niš. Types of errors included were constructed based on the overview of most frequent errors identified in students' exams in the period between 2013 and 2017 (Table 1). The present case study investigated only the correlative conjunction 'not only ... but also', owing to its high frequency of occurrence in course materials. The ecological validity of the study is warranted by the fact that both during their tutorials and in their exams students are often asked to identify and correct grammatical errors in individual sentences.

The experiment was conducted using Open Sesame 3.1 (Mathôt and Theeuwes 2012), and the moving screens paradigm (Figure 1). The participants were instructed to assess the grammaticality of target sentences after each new element had appeared on the screen. If they believed the sentence to be grammatical up to the given position, they were instructed to press the "L" key on the keyboard, and if the sentence was ungrammatical, the " $A$ " key. The position of accurate/inaccurate answers was counterbalanced between "A" and "L" keyboard keys across participants. The relevant dependent variables recorded by the software included RTs for each element of a given sentence (measured in milliseconds), and response accuracy. The recorded data were then coded into an SPSS database and prepared for subsequent analyses. 


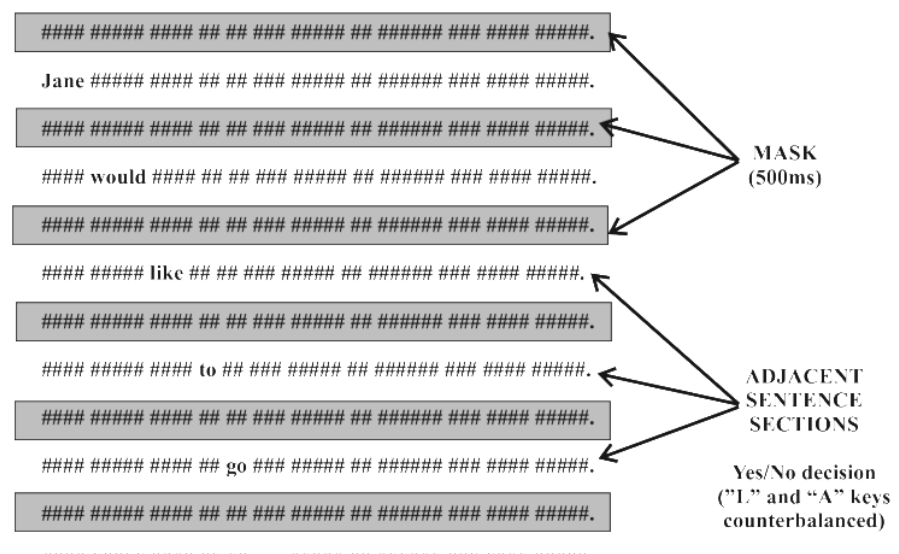

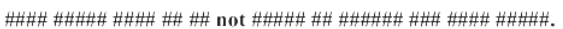

Fig. 1 Masked moving screens

All sentences were presented with a mask, using the 'moving screen paradigm' (Figure 1) and the duration of each masked fixation between the two adjacent sections of the sentence was set at 500ms. The first part of the experiment included a practice loop that consisted of three sentences, after which the participants were instructed to proceed to the main part of the experiment. The main part of the experiment included 17 sentences (Table 1), the order of which was counterbalanced across participants, and each participant was randomly assigned to one of the two experimental conditions. All sentences were displayed on a 15.6" screen of a Toshiba Satellite C55A laptop.

\section{ANALYSIS AND RESULTS}

The present section will address the target stimuli based on the types of errors they contain:

- PHRASe VS. Clause: sentences 1, 6, 8, 9, and 15;

- -ING PHRASE VS. CLAUSE: sentences 2, 13, and 16;

- -ING PHRASE VS. TO-INFINITIVE PHRASE: sentences 3, 4, 7, and 17;

- PREPOSITIONAL PHRASE VS. NOUN PHRASE: sentences 5, 10 and 12; and

- NOUN PHRASE VS. VERB PHRASE: sentences 11 and 14.

\subsection{Error type 1: PHRASE VS. CLAUSE}

\subsubsection{Sentence 1}

In Sentence 1 (Jack not only likes cookies but also *chocolate.), the violation of parallel structure is reflected in the discrepancy between a verb phrase in the first part (likes cookies) and a noun phrase in the second part (chocolate). The error was located in the $8^{\text {th }}$ position in the sentence, and the recorded RTs indeed show an increase in RT between the $8^{\text {th }}$ and the preceding two positions (Figure 2). 


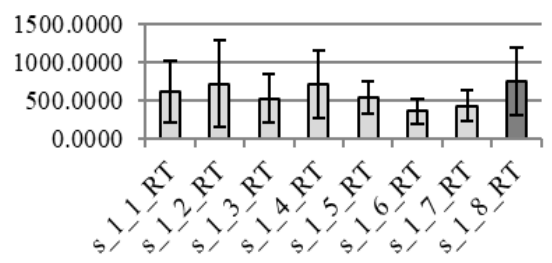

Fig. 2 RTs for Sentence 1

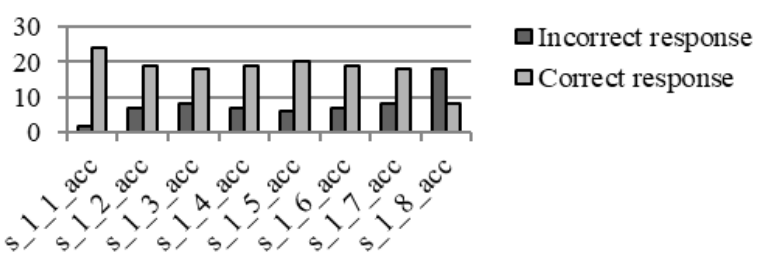

Fig. 3 Accuracy for Sentence 1

Repeated measures ANOVA revealed a significant difference in mean values between the final, and the preceding two positions: (i) $\mathrm{RT}_{8}$ and $\mathrm{RT}_{7}\left(\mathrm{M}_{8}=700.05 \mathrm{~ms}, \mathrm{SD}_{8}=373.91 \mathrm{~ms}\right.$, $\left.\mathrm{M}_{7}=385.05 \mathrm{~ms}, \mathrm{SD}_{7}=158.46 \mathrm{~ms}, \mathrm{p}=.003\right)$; (ii) $\mathrm{RT}_{8}$ and $\mathrm{RT}_{6}\left(\mathrm{M}_{8}=700.05 \mathrm{~ms}, \mathrm{SD}_{8}=373.91 \mathrm{~ms}\right.$, $\mathrm{M}_{6}=338.43 \mathrm{~ms}, \mathrm{SD}_{6}=140.12 \mathrm{~ms}, \mathrm{p}=.001$ ).

In terms of response accuracy, Figure 3 shows a stable ratio of correct/incorrect responses up until the error. In the final position, on the other hand, the ratio tendency suddenly changes, and there is an increase in the number of incorrect responses. Still, the difference between correct and incorrect responses did not reach statistical significance $\left(\mathrm{IR}_{8}=18, \mathrm{CR}_{8}=8\right.$, Chi-square $\left.=3.85, \mathrm{p}=.05\right)$.

The obtained results show a correlation between the lag in RT and the increase of inaccurate responses in the final sentence position where the error occurred. Increased RT suggests processing difficulties caused by the violation of expectancies related to the abstract pattern of parallel structure, while the sudden increase in the number of inaccurate responses suggests that, although apparently present, the pattern of parallel structure has not yet been fully acquired.

\subsubsection{Sentence 6}

In Sentence 6 (Not only would Bob like to visit France but also *Spain.), the first part of parallel structure contains a clause (would Bob like to visit France), while the second part contains only a noun phrase (Spain). The error is located in the $11^{\text {th }}$ position in the sentence, and similar to Sentence 1, there is also a sudden increase in RT recorded in this sentence position (Figure 4). 


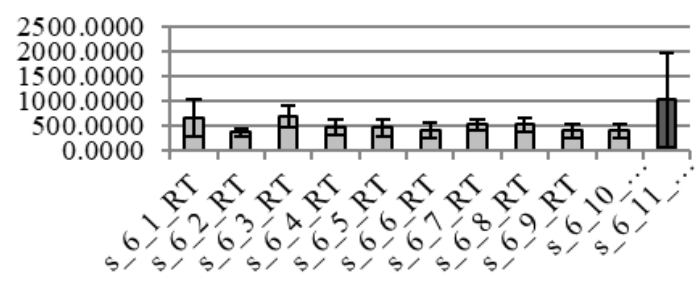

Fig. 4 RTs for Sentence 6

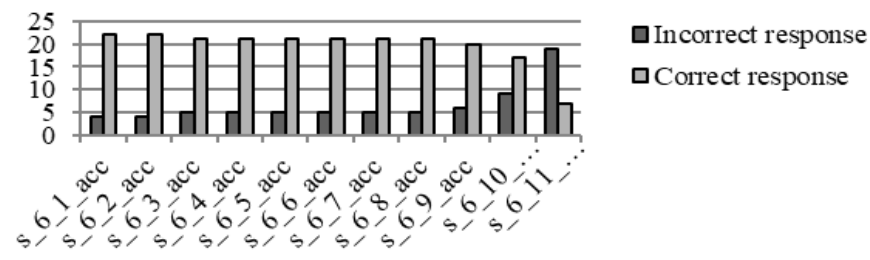

Fig. 5 Accuracy for Sentence 6

Repeated measures ANOVA again showed a significant difference in mean values between the final (error) position and the preceding two positions: (i) $\mathrm{RT}_{11}$ and $\mathrm{RT}_{10}$ $\left(\mathrm{M}_{11}=1026.08 \mathrm{~ms}, \mathrm{SD}_{11}=942.96 \mathrm{~ms}, \mathrm{M}_{10}=399.85 \mathrm{~ms}, \mathrm{SD}_{10}=143.90 \mathrm{~ms}, \mathrm{p}=.046\right.$, suggesting marginal significance); (ii) $\mathrm{RT}_{11}$ and $\mathrm{RT}_{9}\left(\mathrm{M}_{11}=1026.08 \mathrm{~ms}, \mathrm{SD}_{11}=942.96 \mathrm{~ms}, \mathrm{M}_{9}=401 \mathrm{~ms} .74\right.$, $\mathrm{SD}_{9}=135.77 \mathrm{~ms}, \mathrm{p}=.040$ ). Increased $\mathrm{RT}$ in the error-position suggests processing difficulties caused, most likely, by the discrepancy between the generalized pattern of parallel structure and the identified violation of the pattern in the current sentence. As seen in Figure 5, the ratio of accurate/inaccurate responses is stable up to the error position where there is a sudden increase in the number of inaccurate responses which is significantly higher compared to the accurate ones: $\mathrm{IR}_{11}=19, \mathrm{CR}_{11}=7$, chi-square $=5.54, \mathrm{p}=.019, \mathrm{df}=1$.

\subsubsection{Sentence 8}

In Sentence 8 (Jack not only plays the guitar but also *drums) there is a similar violation of parallel structure identified in the first sentence. Namely, the first part contains a verb phrase (plays the guitar), whereas the second part contains only a noun phrase (drums). The overview of RTs (Figure 6) shows an increase in average RT in the final error position, which is also significantly higher compared to the $7^{\text {th }}$ and $8^{\text {th }}$ position: (i) $\mathrm{RT}_{9}$ and $\mathrm{RT}_{7}\left(\mathrm{M}_{9}=1008.89 \mathrm{~ms}, \mathrm{SD}_{9}=679.24 \mathrm{~ms}, \mathrm{M}_{7}=360.21 \mathrm{~ms}, \mathrm{SD}_{7}=153.97 \mathrm{~ms}, \mathrm{p}=.001\right.$, partial eta squared=.68); (ii) $\mathrm{RT}_{9}$ and $\mathrm{RT}_{8} \quad\left(\mathrm{M}_{9}=1008.89 \mathrm{~ms}, \mathrm{SD}_{9}=679.24 \mathrm{~ms}, \mathrm{M}_{8}=429.89 \mathrm{~ms}\right.$, $\mathrm{SD}_{8}=181.53 \mathrm{~ms}, \mathrm{p}=.009$, partial eta squared $\left.=.68\right)$.

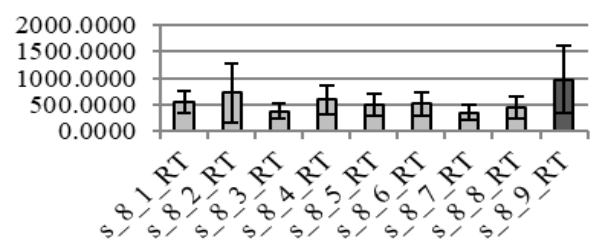

Fig. 6 RTs for Sentence 8 
Figure 7 again reveals an increase in the number of inaccurate answers, which is higher compared to the accurate ones, and which in turn violates the ratio of accurate/inaccurate answers in the preceding parts of the sentence: $\mathrm{IR}_{9}=18, \mathrm{CR}_{8}=8$, chi-square $=3.85, \mathrm{p}=.05$, $\mathrm{df}=1$. The identified significantly higher $\mathrm{RT}$ in the error position again suggests processing difficulties that can be attributed to the violation of expectancies.

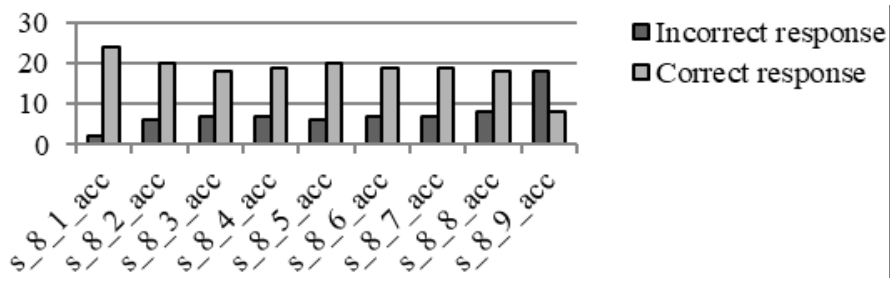

Fig. 7 Accuracy for Sentence 8

\subsubsection{Sentence 9}

The first part of parallel structure in Sentence 9 (Not only does Bill play the saxophone but also *the trumpet) contains a clause (does Bill play the saxophone), while the second part contains a noun phrase (the trumpet). Figure 8 shows the distribution of average RTs for each part of the sentence, and it can be concluded that with this sentence there was a delay in RT linked to the error position. Namely, the lag in RT did not occur in the error position (the $10^{\text {th }}$ position), but one position later (the $11^{\text {th }}$ position). Repeated measures ANOVA showed a significant lag between the final two positions $\left(M_{9}=471.4 \mathrm{~ms}\right.$, $\mathrm{SD}_{9}=192.45 \mathrm{~ms}, \mathrm{M}_{10}=459.00 \mathrm{~ms}, \mathrm{SD}_{10}=198.90 \mathrm{~ms}, \mathrm{M}_{11}=689.70, \mathrm{SD}_{11}=434.73, \mathrm{p}_{9,11}=.193$, $\mathrm{p}_{10,11}=.042$, partial eta squared=.29). Such spillover between the error position and the subsequent position can be explained by the fact that the final two sentence positions are occupied by the definite article and noun (the trumpet), suggesting that the lag in RT occurred only after the entire NP had been fully processed.

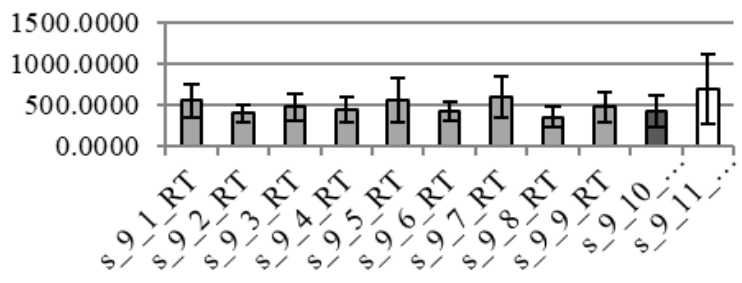

Fig. 8 RTs for Sentence 9

Figure 9 shows an increase in the number of inaccurate responses in both the original error position $\left(10^{\text {th }}\right.$ position) and the subsequent position $\left(11^{\text {th }}\right.$ position): $\mathrm{IR}_{10}=16$, $\mathrm{CR}_{10}=10$, chi-square $=1.39, \mathrm{df}=1, \mathrm{p}=.24 ; \mathrm{IR}_{11}=20, \mathrm{CR}_{11}=6$, chi-square $=7.54, \mathrm{df}=1, \mathrm{p}=.006$. It can be concluded that the increase in RT just after the error position is coupled with the significantly higher count of inaccurate responses in that same position. The recorded increase in RT can again be linked to the violation of parallel structure. 


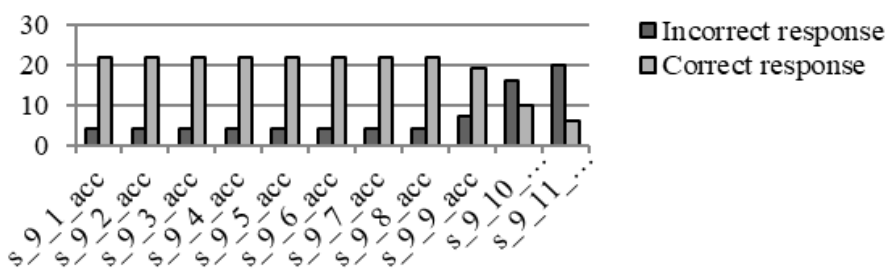

Fig. 9 Accuracy for Sentence 9

\subsubsection{Sentence 15}

In Sentence 15 the grammatical violation of parallel structure is reflected in the discrepancy between the VP in the first part and the AdjP in the second part (Not only $\underline{\text { s }}$ Sarah beautiful but also *intelligent). Repeated measures ANOVA did not reveal any significant difference in RTs between the error position ( $8^{\text {th }}$ position) and the preceding two positions $\left(6^{\text {th }}\right.$ and $\left.7^{\text {th }}\right)$, which suggests that there were no processing difficulties associated with this part of the sentence, i.e. it seems that the participants have failed to 'activate' the appropriate pattern of parallel structure (Figure 10).

The analysis of accuracy (Figure 11) shows a sudden increase in the number of inaccurate responses in the error position ( $8^{\text {th }}$ position), which also showed statistical significance: $\mathrm{IR}_{8}=22, \mathrm{CR}_{8}=4$, chi-square $=12.46, \mathrm{df}=1, \mathrm{p}<.005$. Combined with the results obtained from the analysis of RTs, these findings suggest that the failure to 'activate' the proper pattern of parallel structure has led directly to an unusually high number of inaccurate responses.

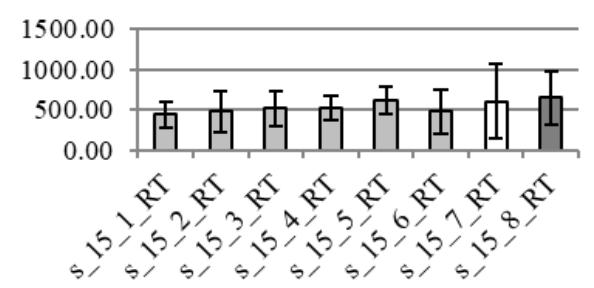

Fig. 10 RTs for Sentence 15

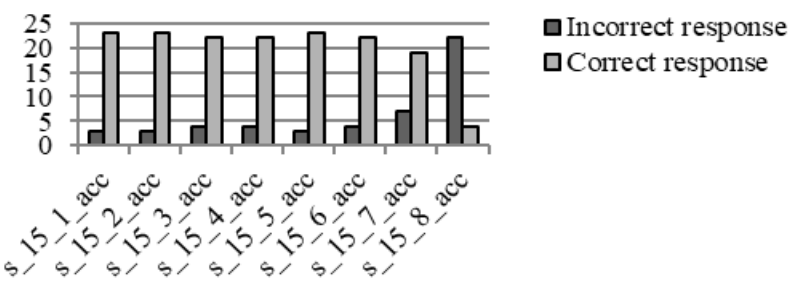

Fig. 11 Accuracy for Sentence 15 


\subsection{Error type 2: -ing phrase vs. clause}

\subsubsection{Sentence 2}

The first part of the parallel structure in Sentence 2 contains an -ing phrase, while the second part contains a complete clause (Sam likes not only reading books but also *he likes watching movies). The analysis of RTs revealed an increase in RT for the error position $\left(9^{\text {th }}\right.$ position $)$ compared to the preceding two and the remaining three subsequent positions (Figure 12).

Repeated measures ANOVA showed a significant difference in mean values in the following cases: (i) $\mathrm{RT}_{9}$ and $\mathrm{RT}_{7} \quad\left(\mathrm{M}_{9}=721.00 \mathrm{~ms}, \mathrm{SD}_{9}=648.28 \mathrm{~ms}, \mathrm{M}_{7}=347.22 \mathrm{~ms}\right.$, $\left.\mathrm{SD}_{7}=151.77 \mathrm{~ms}, \mathrm{p}=.004\right)$; (ii) $\mathrm{RT}_{9}$ and $\mathrm{RT}_{8}\left(\mathrm{M}_{9}=721.00 \mathrm{~ms}, \mathrm{SD}_{9}=648.28 \mathrm{~ms}, \mathrm{M}_{8}=336.28 \mathrm{~ms}\right.$, $\left.\mathrm{SD}_{8}=173.51 \mathrm{~ms}, \mathrm{p}=.022\right)$; (iii) $\mathrm{RT}_{9}$ and $\mathrm{RT}_{10}\left(\mathrm{M}_{9}=721.00 \mathrm{~ms}, \mathrm{SD}_{9}=648.28 \mathrm{~ms}, \mathrm{M}_{10}=343.00 \mathrm{~ms}\right.$, $\left.\mathrm{SD}_{10}=135.60 \mathrm{~ms}, \mathrm{p}=.004\right)$; and (iv) RT9 and RT12 $\left(\mathrm{M}_{9}=721.00 \mathrm{~ms}, \mathrm{SD}_{9}=648.28 \mathrm{~ms}\right.$, $\left.\mathrm{M}_{12}=344.47 \mathrm{~ms}, \mathrm{SD}_{12}=149.26 \mathrm{~ms}, \mathrm{p}=.010\right)$. The difference in RTs between the $9^{\text {th }}$ and $11^{\text {th }}$ position was not significant $\left(\mathrm{M}_{9}=721.00 \mathrm{~ms}, \mathrm{SD}_{9}=648.28 \mathrm{~ms}, \mathrm{M}_{11}=539.00 \mathrm{~ms}, \mathrm{SD}_{11}=233.06 \mathrm{~ms}\right.$, $\mathrm{p}=.12$ ).

Additionally, there was an unexpected early increase in RT in the $3^{\text {rd }}$ position, which can be attributed to word order in the initial part of the sentence. Namely, the negation usually precedes the verb (e.g. Sam doesn't like...), which is the most frequent syntactic form the participants are used to. In the present case, the negative particle 'not' comes after the verb (Sam likes not only...), which has obviously caused some processing difficulties. The $4^{\text {th }}$ position clarifies the word order typical of parallel structure and there is again a decrease in RT, which is significantly lower compared to RT in the previous position $\left(\mathrm{M}_{3}=849.67 \mathrm{~ms}, \mathrm{SD}_{3}=619.50 \mathrm{~ms}, \mathrm{M}_{4}=552.46 \mathrm{~ms}, \mathrm{SD}_{4}=281.81 \mathrm{~ms}\right.$, partial eta squared=.22, $\mathrm{p}=.019)$. Despite the processing difficulties, the analysis of accuracy did not show any significant drop in the number of accurate responses in the $3^{\text {rd }}$ position (Figure 13).

Figure 13 gives an overview of response accuracy for Sentence 2 and it can be concluded that, starting from the error position $\left(9^{\text {th }}\right.$ position) until the end of the sentence, the number of incorrect responses increases compared to the recorded accuracy in the preceding parts of the sentence, and it is almost equal to the number of accurate responses. It can be concluded that the increase in RT linked to the error caused an offset in the ratio between accurate/inaccurate responses, and this offset was not constrained to the error position alone, but it continued until the end of the sentence: (i) $\mathrm{IR}_{9}=12, \mathrm{CR}_{9}=14$, chisquare $=0.15, \mathrm{df}=1, \mathrm{p}=.70$; (ii) $\mathrm{IR}_{10}=11, \mathrm{CR}_{10}=15$, chi-square $=0.62, \mathrm{df}=1, \mathrm{p}=.43$; (iii) $\mathrm{IR}_{11}=11$, $\mathrm{CR}_{11}=15$, chi-square=0.62, $\mathrm{df}=1, \mathrm{p}=.43$; (iv) $\mathrm{IR}_{12}=14, \mathrm{CR}_{12}=12$, chi-square $=0.15, \mathrm{df}=1, \mathrm{p}=.70$.

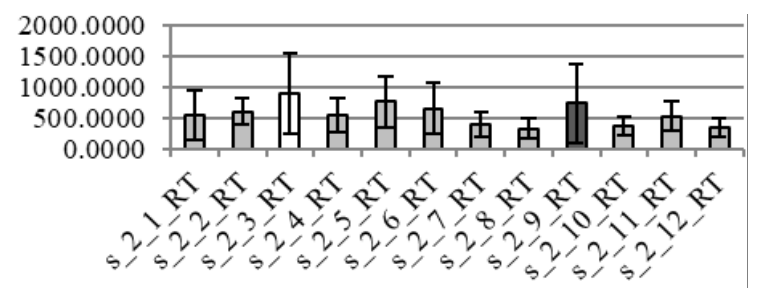

Fig. 12 RTs for Sentence 2 


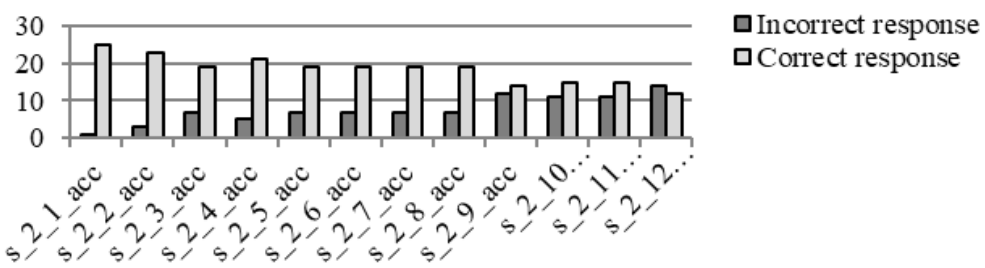

Fig. 13 Accuracy for Sentence 2

In turn, it can be concluded that the lag in RT related to the violation of parallel structure signals that the abstract grammatical pattern from L2 is indeed present; the drop in the number of accurate solutions starting from the error onward also brings into question the level to which the abstract pattern has been acquired. However, it appears that the participants performed better in terms of accuracy, compared to the first group of sentences where the error was located in the sentence final position, while here it is located in the second half of the sentence.

\subsubsection{Sentence 13}

In Sentence 13 the parallel structure is violated with the -ing phrase in the first part and a clause in the second (Peter enjoys not only hiking but also *he enjoys swimming). Figure 14 shows a rapid increase in RT located in the error position ( $8^{\text {th }}$ position). Repeated measures ANOVA showed a significant difference in RTs between the error position and both the two preceding and subsequent positions: (i) $\mathrm{RT}_{8}$ and $\mathrm{RT}_{6}\left(\mathrm{M}_{8}=2206.94 \mathrm{~ms}, \mathrm{SD}_{8}=438.33 \mathrm{~ms}\right.$, $\left.\mathrm{M}_{6}=388.35 \mathrm{~ms}, \mathrm{SD}_{6}=152.23 \mathrm{~ms}, \mathrm{p}=.009\right)$; (ii) $\mathrm{RT}_{8}$ and $\mathrm{RT}_{7}\left(\mathrm{M}_{8}=2206.94 \mathrm{~ms}, \mathrm{SD}_{8}=438.33 \mathrm{~ms}\right.$, $\mathrm{M}_{7}=398.24 \mathrm{~ms}, \mathrm{SD}_{7}=116.01 \mathrm{~ms}, \mathrm{p}=.008$ ); (iii) $\mathrm{RT}_{8}$ and $\mathrm{RT}_{9}\left(\mathrm{M}_{8}=2206.94 \mathrm{~ms}, \mathrm{SD}_{8}=438.33 \mathrm{~ms}\right.$, $\left.\mathrm{M}_{9}=875.71 \mathrm{~ms}, \quad \mathrm{SD}_{9}=696.90 \mathrm{~ms}, \mathrm{p}=.004\right) ;$ and (iv) $\mathrm{RT}_{8}$ and $\mathrm{RT}_{10} \quad\left(\mathrm{M}_{8}=2206.94 \mathrm{~ms}\right.$, $\left.\mathrm{SD}_{8}=438.33 \mathrm{~ms}, \mathrm{M}_{10}=694.18 \mathrm{~ms}, \mathrm{SD}_{10}=456.66 \mathrm{~ms}, \mathrm{p}<.005\right)$. Such a substantial increase in RT signals processing difficulties that can be associated with the discrepancy between the abstract pattern of parallel structure and the present grammatical violation.

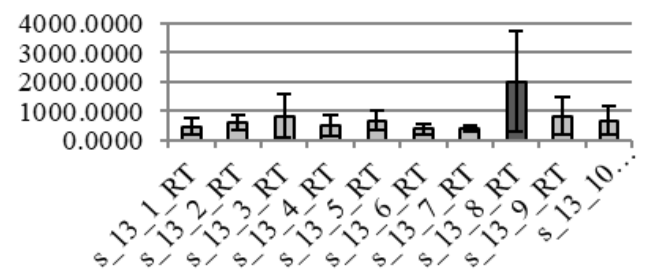

Fig. 14 RTs for Sentence 13

Like in the previous sentence, the lag in RT caused by the violation of the parallel structure is coupled with a sudden increase in the number of incorrect responses (Figure 15), and this tendency continues toward the end of the sentence, even after the error position: (i) $\mathrm{IR}_{8}=11, \mathrm{CR}_{8}=15$, chi-square $=0.62, \mathrm{df}=1, \mathrm{p}=.43$; (ii) $\mathrm{IR}_{9}=12, \mathrm{CR}_{9}=14$, chisquare $=0.15, \mathrm{df}=1, \mathrm{p}=.70$; (iii) $\mathrm{IR}_{10}=12, \mathrm{CR}_{10}=14$, chi-square $=0.15, \mathrm{df}=1, \mathrm{p}=.70$. Again, it appears that the location of the error afforded a higher rate of accuracy in the grammaticality judgment task compared to the first group of sentences (see section 4.1). 


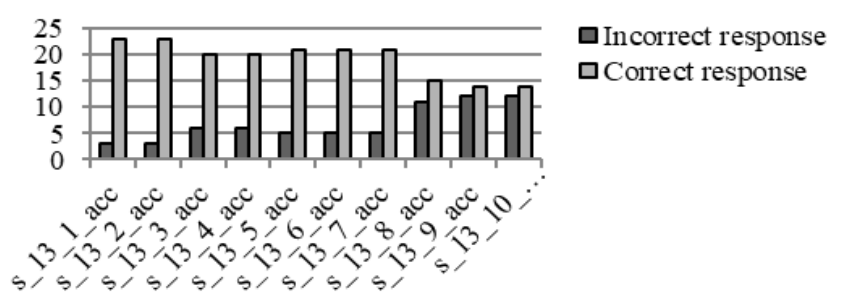

Fig. 15 Accuracy for Sentence 13

\subsubsection{Sentence 16}

In Sentence 16, the first part of the parallel structure contains a clause, while the second part contains an -ing phrase (Not only does Paul enjoy sailing but also *paragliding). Repeated measures ANOVA revealed a significantly higher RT in the error position compared to the two preceding positions (Figure 16): (i) $\mathrm{RT}_{9}$ and $\mathrm{RT}_{7}\left(\mathrm{M}_{9}=785.76 \mathrm{~ms}\right.$, $\mathrm{SD}_{9}=370.51 \mathrm{~ms}, \mathrm{M}_{7}=351.59 \mathrm{~ms}, \mathrm{SD}_{7}=135.63 \mathrm{~ms}, \mathrm{p}=.001$, partial eta squared=.58); (ii) $\mathrm{RT}_{9}$ and $\mathrm{RT}_{8} \quad\left(\mathrm{M}_{9}=785.76 \mathrm{~ms}, \mathrm{SD}_{9}=370.51 \mathrm{~ms}, \mathrm{M}_{8}=436.06 \mathrm{~ms}, \mathrm{SD}_{8}=132.56 \mathrm{~ms}, \mathrm{p}=.002\right.$, partial eta squared=.58).

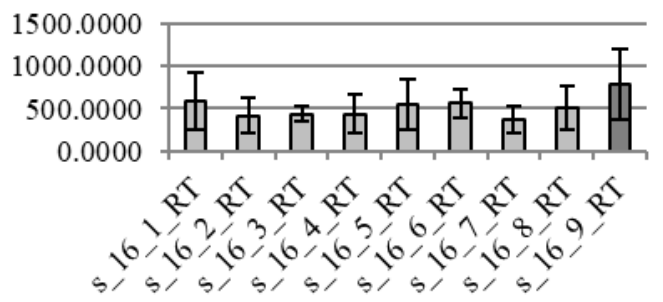

Fig. 16 RTs for Sentence 16

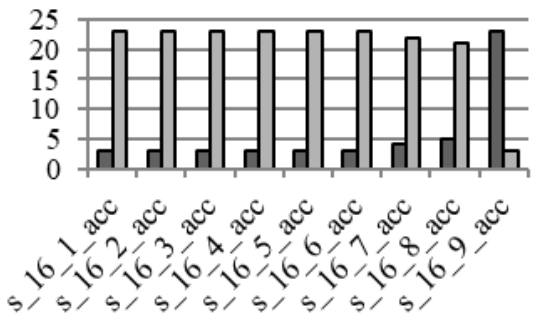

$\square$ Incorrect response

口Correct response

Fig. 17 Accuracy for Sentence 16

Analysis of accuracy (Figure 17) revealed a significant increase in the number of incorrect responses compared to correct ones in the error position: $\mathrm{IR}_{9}=23, \mathrm{CR}_{9}=3$, chisquare $=15.39, \mathrm{df}=1, \mathrm{p}<.005$. The previously identified significant increase in $\mathrm{RT}$ in the error position signals a certain level of processing difficulty caused by the violation of parallel structure and the corresponding expectancies. 


\subsection{Error type 3: -ing phrase vs. to-infinitive phrase}

\subsubsection{Sentence 3}

In Sentence 3, the first part of the parallel structure contains an -ing form, while the second part contains a to-infinitive form (Sarah not only enjoys skiing but also enjoys * go to the seaside). The analysis of RTs in this case shows a delay in RT in the position preceding the error position.

Repeated measures ANOVA did not show a significant difference in RTs between the error position ( $9^{\text {th }}$ position) and the preceding position $\left(8^{\text {th }}\right.$ position; $\left.p=.21\right)$, while the RT in the error position was significantly higher compared to subsequent RTs in the remaining positions: (i) $\mathrm{RT}_{9}$ and $\mathrm{RT}_{10}\left(\mathrm{M}_{9}=732.29 \mathrm{~ms}, \mathrm{SD}_{9}=563.54 \mathrm{~ms}, \mathrm{M}_{10}=449.65 \mathrm{~ms}\right.$, $\mathrm{SD}_{10}=235.90 \mathrm{~ms}, \mathrm{p}=.008$, partial eta squared=.52); (ii) $\mathrm{RT}_{9}$ and $\mathrm{RT}_{11}\left(\mathrm{M}_{9}=732.29 \mathrm{~ms}\right.$, $\mathrm{SD}_{9}=563.54 \mathrm{~ms}, \mathrm{M}_{11}=293.71 \mathrm{~ms}, \mathrm{SD}_{11}=137.16 \mathrm{~ms}, \mathrm{p}=.001$, partial eta squared=.52); (iii) $\mathrm{RT}_{9}$ and $\mathrm{RT}_{12}\left(\mathrm{M}_{9}=732.29 \mathrm{~ms}, \mathrm{SD}_{9}=563.54 \mathrm{~ms}, \mathrm{M}_{12}=291.00 \mathrm{~ms}, \mathrm{SD}_{12}=127.83 \mathrm{~ms}, \mathrm{p}=.004\right.$, partial eta squared=.52); (iv) $\mathrm{RT}_{9}$ and $\mathrm{RT}_{13} \quad\left(\mathrm{M}_{9}=732.29 \mathrm{~ms}, \quad \mathrm{SD}_{9}=563.54 \mathrm{~ms}, \mathrm{M}_{13}=332.47 \mathrm{~ms}\right.$, $\mathrm{SD}_{13}=259.37 \mathrm{~ms}, \mathrm{p}=.022$, partial eta squared $=.52$ ).

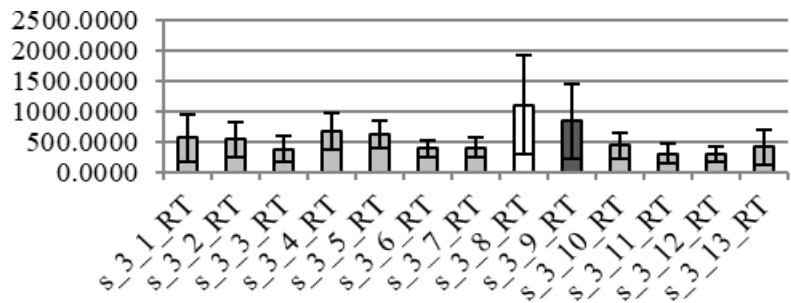

Fig. 18 RTs for Sentence 3

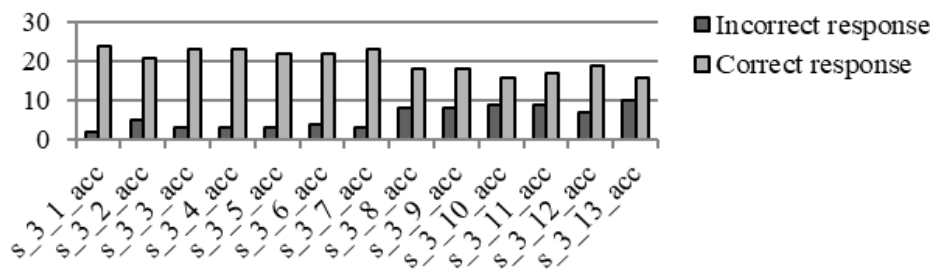

Fig. 19 Accuracy for Sentence 3

Figure 19 shows a small decrease in accuracy starting from the error position $\left(9^{\text {th }}\right.$ position), until the end of the sentence. However, unlike the previous cases, the number of accurate responses remains higher compared to inaccurate ones. The difference in the count of correct/incorrect responses did not reach significance in the error position: $\mathrm{IR}_{9}=8, \mathrm{CR}_{9}=18$, chi-square $=3.85, \mathrm{df}=1, \mathrm{p}=.05$.

The analysis of RTs suggests that the abstract pattern is present, although the lag in RT did not occur precisely in the error position. The ratio of accurate/inaccurate responses and the higher count of accurate responses suggest that most of the participants were able to correctly assess the grammaticality of the sentence. Coupled with the lag in 
RT associated with the violation of parallel structure, it can be concluded that the participants were much more successful in error identification in the context where the error is located in the second half of the sentence, rather than in the sentence-final position (like in section 4.1).

\subsubsection{Sentence 4}

In Sentence 4 the violation of the parallel structure is reflected in the discrepancy between the -ing phrase in the first part, and the to-infinitive form in the second (Peter wants to go not only swimming but also *to ride his bicycle). The analysis of RTs (Figure 20) shows an unusual delay in the $7^{\text {th }}$ position, which is also significantly higher compared to the delay in the error position $\left(10^{\text {th }}\right.$ position): $\mathrm{M}_{7}=1244.17 \mathrm{~ms}, \mathrm{SD}_{7}=815.33 \mathrm{~ms}$, $\mathrm{M}_{10}=604.78 \mathrm{~ms}, \mathrm{SD}_{10}=526.26 \mathrm{~ms}$, partial eta squared=.34, $\mathrm{p}=.003$. The subsequent analysis of accuracy also shows a sudden drop in the number of accurate responses that persists from the $7^{\text {th }}$ to $9^{\text {th }}$ positions which represent accurate parts of the sentence (Figure 21).

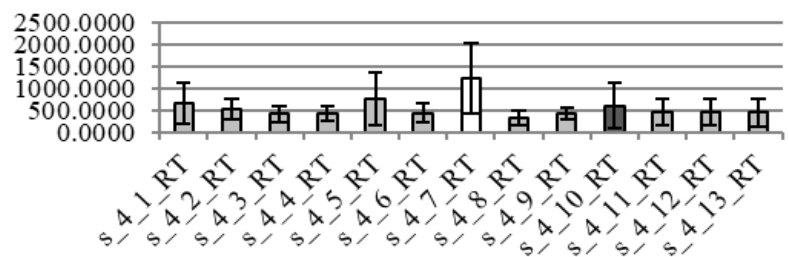

Fig. 20 RTs for Sentence 4

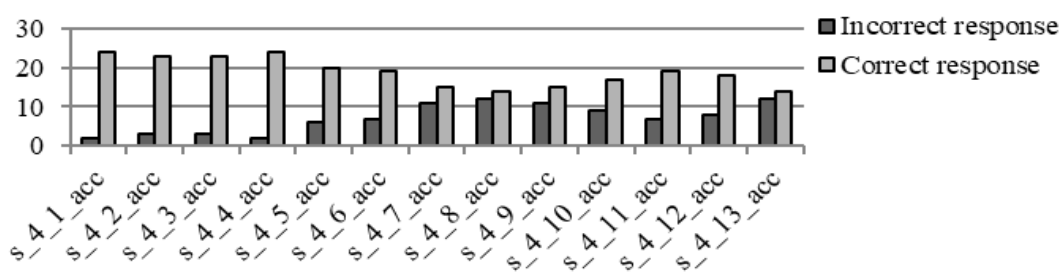

Fig. 21 Accuracy for Sentence 4

Repeated measures ANOVA did not reveal any significant differences between RT in the error position and in the $8^{\text {th }}, 9^{\text {th }}, 11^{\text {th }}, 12^{\text {th }}$, and $13^{\text {th }}$ position. This in turn suggests that there were no processing difficulties associated with the violation of parallel structure in the error position. On the other hand, the accuracy level in the error position is quite high (Figure 21) and is maintained through the subsequent two positions $\left(11^{\text {th }}\right.$ and $\left.12^{\text {th }}\right)$.

\subsubsection{Sentence 7}

The violation of the parallel structure in Sentence 7 is reflected in the difference between the first part that contains a clause with a to-infinitive phrase and the second part that contains an -ing phrase (Not only is the car easy to drive but also *traveling comfortably). Figure 22 shows an increase in RT both in the immediate error position $\left(11^{\text {th }}\right.$ position $)$ and in the subsequent position, which suggests processing difficulties associated with the violation of 
parallel structure. Repeated measures ANOVA showed a significant difference in RTs in the following cases: (i) $\mathrm{RT}_{11}$ and $\mathrm{RT}_{9}\left(\mathrm{M}_{11}=1129.82 \mathrm{~ms}, \mathrm{SD}_{11}=446.28 \mathrm{~ms}, \mathrm{M}_{9}=334.94 \mathrm{~ms}\right.$, $\left.\mathrm{SD}_{9}=98.66 \mathrm{~ms}, \mathrm{p}<.005\right)$; (ii) $\mathrm{RT}_{11}$ and $\mathrm{RT}_{10} \quad\left(\mathrm{M}_{11}=1129.82 \mathrm{~ms}, \mathrm{SD}_{11}=446.28 \mathrm{~ms}\right.$, $\left.\mathrm{M}_{10}=676.88 \mathrm{~ms}, \quad \mathrm{SD}_{10}=608.66 \mathrm{~ms}, \mathrm{p}=.032\right)$; (iii) RT11 and RT12 $\left(\mathrm{M}_{11}=1129.82 \mathrm{~ms}\right.$, $\left.\mathrm{SD}_{11}=446.28 \mathrm{~ms}, \mathrm{M}_{12}=729.76 \mathrm{~ms}, \mathrm{SD}_{12}=558.87 \mathrm{~ms}, \mathrm{p}=.005\right)$. The recorded spillover from the error to the subsequent position can be attributed to the fact that it is located in the sentence final position; in effect, the delay in RT continued until the whole sentence was processed.

The analysis of accuracy (Figure 23) did not show any changes in the ratio of correct/incorrect responses, and the difference in the error position is even more in favor of correct responses $\left(\mathrm{IR}_{11}=1, \mathrm{CR}_{11}=24\right.$, chi-square $\left.=18.62, \mathrm{df}=1, \mathrm{p}<.005\right)$. It can be concluded that in the present case the lag in RT did not lead to a drop in correct responses as it was the case in previous sentences.

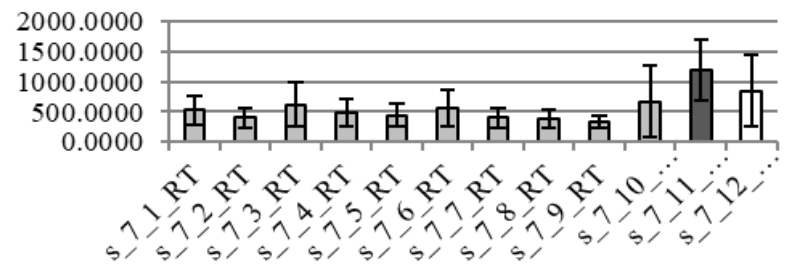

Fig. 22 RTs for Sentence 7

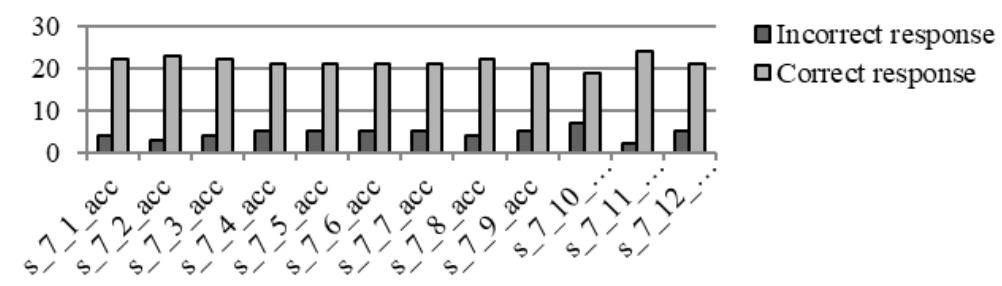

Fig. 23 Accuracy for Sentence 7

\subsubsection{Sentence 17}

The first part of the parallel structure in Sentence 17 contains a clause with an -ing phrase, while the second part contains a to-infinitive phrase (Not only does Sarah like reading but also *to go to the cinema). Analysis of RTs (Figure 24) revealed a huge lag at the onset of the sentence in the first position, which can be attributed to inversion (not only does...); however, despite the lag, the accuracy level in this position is very high $\left(\mathrm{IR}_{1}=3, \mathrm{CR}_{1}=23\right.$, chi-square $\left.=15.39, \mathrm{df}=1, \mathrm{p}<.005\right)$. It can be concluded that the increased RT reveals processing difficulties, while the high accuracy count shows that the pattern for inversion at the beginning of a sentence starting with the correlative conjunction not only ... but also has been successfully acquired.

Repeated measures ANOVA showed a significant difference between the RT in the error position ( $9^{\text {th }}$ position) and the following sentence positions: (i) $\mathrm{RT}_{9}$ and $\mathrm{RT}_{7}\left(\mathrm{M}_{9}=935.50 \mathrm{~ms}\right.$, $\mathrm{SD}_{9}=514.16 \mathrm{~ms}, \mathrm{M}_{7}=385.63 \mathrm{~ms}, \mathrm{SD}_{7}=129.04 \mathrm{~ms}, \mathrm{p}=.004$, partial eta squared=.67); (ii) $\mathrm{RT}_{9}$ and $\mathrm{RT}_{8} \quad\left(\mathrm{M}_{9}=935.50 \mathrm{~ms}, \mathrm{SD}_{9}=514.16 \mathrm{~ms}, \mathrm{M}_{8}=458.69 \mathrm{~ms}, \mathrm{SD}_{8}=181.78 \mathrm{~ms}, \mathrm{p}=.005\right.$, partial eta 
squared=.67); (iii) $\mathrm{RT}_{9}$ and $\mathrm{RT}_{11} \quad\left(\mathrm{M}_{9}=935.50 \mathrm{~ms}, \mathrm{SD}_{9}=514.16 \mathrm{~ms}, \mathrm{M}_{11}=421.19 \mathrm{~ms}\right.$, $\mathrm{SD}_{11}=160.19 \mathrm{~ms}, \mathrm{p}=.004$, partial eta squared=.67); (iv) $\mathrm{RT}_{9}$ and $\mathrm{RT}_{12} \quad\left(\mathrm{M}_{9}=935.50 \mathrm{~ms}\right.$, $\mathrm{SD}_{9}=514.16 \mathrm{~ms}, \mathrm{M}_{12}=477.81 \mathrm{~ms}, \mathrm{SD}_{12}=203.31 \mathrm{~ms}, \mathrm{p}=.023$, partial eta squared=.67). The difference between the $9^{\text {th }}$ and $10^{\text {th }}$ position did not reach significance $(\mathrm{p}=.18)$, suggesting that the processing lag continued from the error position to the adjacent position.

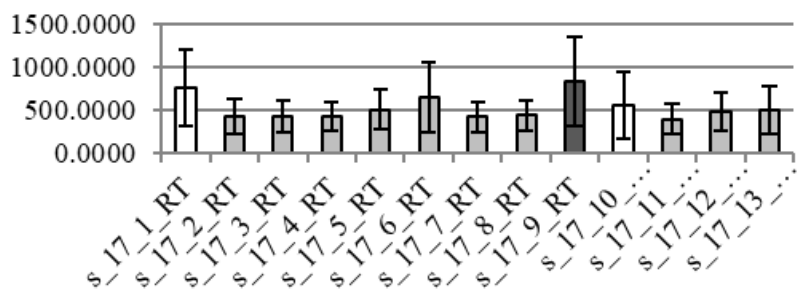

Fig. 24 RTs for Sentence 17

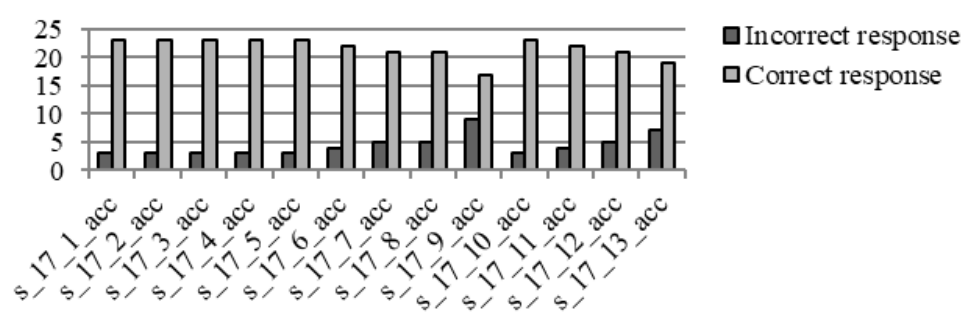

Fig. 25 Accuracy for Sentence 17

The analysis of accuracy (Figure 25) shows a small drop in the number of correct answers in the error position $\left(9^{\text {th }}\right.$ position), compared to the preceding and subsequent positions, but the number of correct answers remains higher compared to incorrect ones, although the difference is not significant: $\mathrm{IR}_{9}=9, \mathrm{CR}_{9}=17$, chi-square $=2.46, \mathrm{df}=1, \mathrm{p}=.12$.

Based on the obtained data for the present sentence it can be concluded that the increased RT in the error position suggests processing difficulties related to the violation of parallel structure, while the ratio of correct/incorrect responses shows that the majority of participants have properly acquired the pattern from the L2.

\subsection{Error type 4: prepositional phrase vs. noun phrase}

\subsubsection{Sentence 5}

The first part of the parallel structure in Sentence 5 contains a PP, while the second part contains only a noun phrase (Jane would like to go not only to France but also *Italy). Repeated measures ANOVA showed a significant difference between the error position ( $12^{\text {th }}$ position) and the preceding two positions (Figure 26): (i) $\mathrm{RT}_{12}$ and $\mathrm{RT}_{11}$ $\left(\mathrm{M}_{12}=823.00 \mathrm{~ms}, \mathrm{SD}_{12}=683.81 \mathrm{~ms}, \mathrm{RT}_{11}=391.06 \mathrm{~ms}, \mathrm{SD}_{11}=161.18 \mathrm{~ms}, \mathrm{p}=.006\right)$; and (ii) $\mathrm{RT}_{12}$ and $\mathrm{RT}_{10}\left(\mathrm{M}_{12}=823.00 \mathrm{~ms}, \mathrm{SD}_{12}=683.81 \mathrm{~ms}, \mathrm{RT}_{10}=321.13 \mathrm{~ms}, \mathrm{SD}_{10}=95.46 \mathrm{~ms}, \mathrm{p}=.001\right)$. 


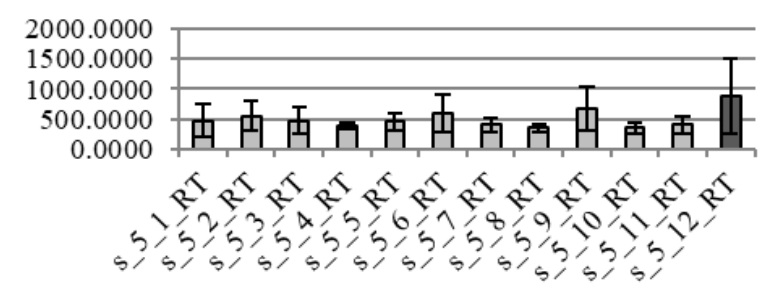

Fig. 26 RTs for Sentence 5

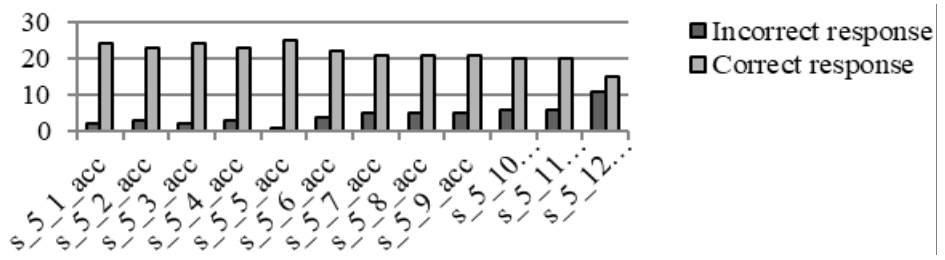

Fig. 27 Accuracy for Sentence 5

The analysis of accuracy (Figure 27) showed a sudden drop in the number of accurate responses in the error position, but their count was still higher compared to inaccurate responses, although the difference did not reach significance $(\mathrm{p}=.43)$.

\subsubsection{Sentence 10}

The first part of the parallel structure in Sentence 10 contains a prepositional phrase, whereas the second part contains only a noun phrase (Bill would like to campaign not only for the governor but also *the senator). Analysis or RTs revealed an unexpected early delay in positions 5 and 6 (... campaign not ...). This can be attributed to the fact that 'campaign' typically appears as a noun, whereas in the present case it is used as a verb. Additionally, the negation is typically introduced before the verb (e.g. not campaign), while here it appears after the verb. However, after the introduction of 'only' in the $7^{\text {th }}$ position, the pattern of parallel structure becomes 'obvious' and there is a significant decrease in RT $\left(\mathrm{M}_{6}=957.64 \mathrm{~ms}\right.$, $\mathrm{SD}_{6}=504.06 \mathrm{~ms}, \mathrm{M}_{7}=460.64 \mathrm{~ms}, \mathrm{SD}_{7}=109.00 \mathrm{~ms}$, partial eta squared=.49, $\mathrm{p}<.005$ ).

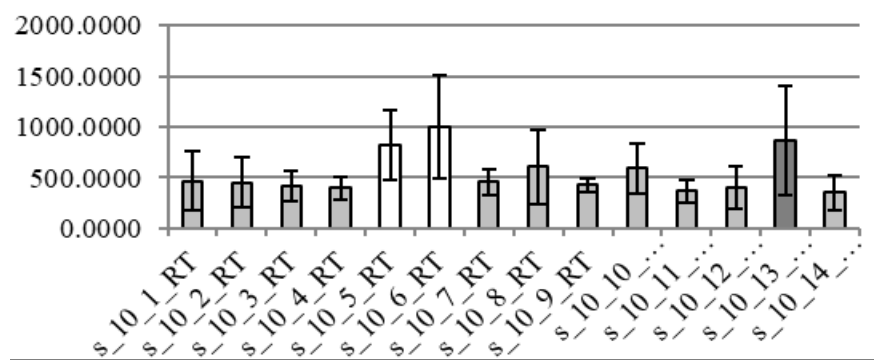

Fig. 28 RTs for Sentence 10 


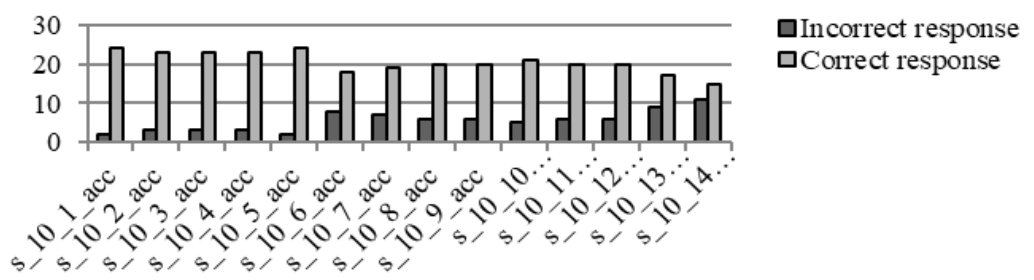

Fig. 29 Accuracy for Sentence 10

The analysis of accuracy (Figure 29), on the other hand, did not reveal any problems in the $5^{\text {th }}$ position as there was a significantly higher count of accurate solutions $\left(\mathrm{IR}_{5}=2, \mathrm{CR}_{5}=24\right.$, chi square $=18.62, \mathrm{df}=1, \mathrm{p}<.005)$. The processing lag identified in the $6^{\text {th }}$ position can be attributed to the overall syntactic structure of the sentence, where the negation through the correlative conjunction is introduced only after the VP has been introduced (... would like to campaign not only for ...). $\mathrm{RT}_{6}$ was even higher than $\mathrm{RT}_{5}$, and there was a drop in the number of accurate responses $\left(\mathrm{IR}_{6}=8, \mathrm{CR}_{6}=18\right.$, chi square $\left.=3.85, \mathrm{df}=1, \mathrm{p}=.05\right)$.

Repeated measures ANOVA showed a significant difference in RTs in the following cases (Figure 28): (i) $\mathrm{RT}_{13}$ and $\mathrm{RT}_{11} \quad\left(\mathrm{M}_{13}=832.45 \mathrm{~ms}, \mathrm{SD}_{13}=615.35 \mathrm{~ms}, \mathrm{M}_{11}=314.36 \mathrm{~ms}\right.$, $\left.\mathrm{SD}_{11}=83.95 \mathrm{~ms}, \mathrm{p}<.005\right)$; (ii) $\mathrm{RT}_{13}$ and $\mathrm{RT}_{12}\left(\mathrm{M}_{13}=832.45 \mathrm{~ms}, \mathrm{SD}_{13}=615.35 \mathrm{~ms}, \mathrm{M}_{12}=326.45 \mathrm{~ms}\right.$, $\left.\mathrm{SD}_{12}=196.63 \mathrm{~ms}, \quad \mathrm{p}<.005\right)$; (iii) $\mathrm{RT}_{13}$ and $\mathrm{RT}_{14} \quad\left(\mathrm{M}_{13}=832.45 \mathrm{~ms}, \mathrm{SD}_{13}=615.35 \mathrm{~ms}\right.$, $\left.\mathrm{M}_{14}=320.00 \mathrm{~ms}, \mathrm{SD}_{14}=164.56 \mathrm{~ms}, \mathrm{p}=.001\right)$.

Accuracy analysis (Figure 29) showed a drop in the number of correct responses in the $13^{\text {th }}$ and $14^{\text {th }}$ position, but the difference between the number of accurate and inaccurate responses in the two positions did not reach significance $\left(\mathrm{p}_{13}=.12, \mathrm{p}_{14}=.43\right)$. This in turn shows that the delay in RT in the error position also caused a decrease in the number of accurate responses.

\subsubsection{Sentence 12}

In Sentence 12, the first part of the parallel structure contains a prepositional phrase, while the second part contains only a noun phrase (Bill and Sarah are going not only to the cinema but also *the theater). Repeated measures ANOVA showed a significant difference in RTs in the following cases (Figure 30): (i) $\mathrm{RT}_{13}$ and $\mathrm{RT}_{11}\left(\mathrm{M}_{13}=1260.40 \mathrm{~ms}, \mathrm{SD}_{13}=909.88 \mathrm{~ms}\right.$, $\left.\mathrm{M}_{11}=328.33 \mathrm{~ms}, \quad \mathrm{SD}_{11}=76.67 \mathrm{~ms}, \mathrm{p}=.007\right) ; \quad$ (ii) $\mathrm{RT}_{13}$ and $\mathrm{RT}_{12} \quad\left(\mathrm{M}_{13}=1260.40 \mathrm{~ms}\right.$, $\mathrm{SD}_{13}=909.88 \mathrm{~ms}, \quad \mathrm{M}_{12}=386.33 \mathrm{~ms}, \quad \mathrm{SD}_{12}=127.53 \mathrm{~ms}, \quad \mathrm{p}=.013$ ); (iii) $\mathrm{RT}_{13}$ and $\mathrm{RT}_{14}$ $\left(\mathrm{M}_{13}=1260.40 \mathrm{~ms}, \mathrm{SD}_{13}=909.88 \mathrm{~ms}, \mathrm{M}_{14}=614.73 \mathrm{~ms}, \mathrm{SD}_{14}=407.86 \mathrm{~ms}, \mathrm{p}=.006\right)$. This again reveals processing difficulties located in the error position, caused by the violation of parallel structure.

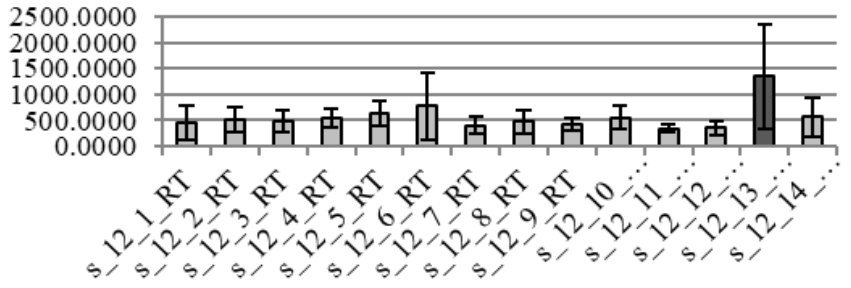

Fig. 30 RTs for Sentence 12 


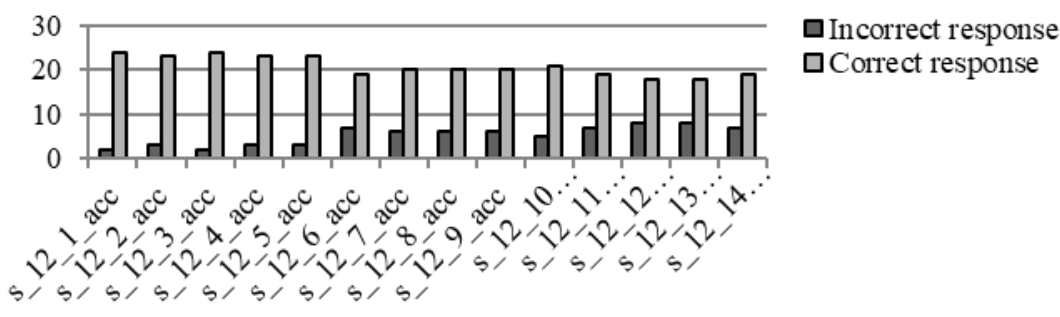

Fig. 31 Accuracy for Sentence 12

Accuracy analysis (Figure 31) revealed a small drop in the number of correct responses, but their number is still higher compared to the number of incorrect responses, although the difference did not reach significance $\left(\mathrm{IR}_{13}=8, \mathrm{CR}_{8}=18\right.$, chi-square $\left.=3.85, \mathrm{df}=1, \mathrm{p}=.05\right)$.

\subsection{Error type 5: verb phrase vs. noun phrase}

\subsubsection{Sentence 11}

The first part of the parallel structure in Sentence 11 contains a verb phrase, while in the second part there is only a noun phrase (The new Volvo is not only easy to drive but also $*$ a great sound system $)$. Figure 32 shows a lag in RT in the error position $\left(12^{\text {th }}\right.$ position), which persists through the subsequent position. Repeated measures ANOVA showed a significant difference in RT between the error position and the two preceding positions, but not with the subsequent position: (i) $\mathrm{RT}_{12}$ and $\mathrm{RT}_{10}\left(\mathrm{M}_{12}=105.23 \mathrm{~ms}\right.$, $\mathrm{SD}_{12}=365.59 \mathrm{~ms}, \quad \mathrm{M}_{10}=321.65 \mathrm{~ms}, \quad \mathrm{SD}_{10}=137.55 \mathrm{~ms}, \mathrm{p}=.007$ ); (ii) $\mathrm{RT}_{12}$ and $\mathrm{RT}_{11}$ $\left(\mathrm{M}_{12}=105.23 \mathrm{~ms}, \mathrm{SD}_{12}=365.59 \mathrm{~ms}, \mathrm{M}_{11}=376.88 \mathrm{~ms}, \mathrm{SD}_{11}=250.16 \mathrm{~ms}, \mathrm{p}=.018\right)$; (iii) $\mathrm{RT}_{12}$ and $\mathrm{RT}_{13}\left(\mathrm{M}_{12}=105.23 \mathrm{~ms}, \mathrm{SD}_{12}=365.59 \mathrm{~ms}, \mathrm{M}_{13}=904.32 \mathrm{~ms}, \mathrm{SD}_{13}=774.71 \mathrm{~ms}, \mathrm{p}=.621\right)$. These results reveal processing difficulties that continue through the subsequent position following the error. The recorded spillover between the error and the subsequent position can be attributed to the fact that these two positions are occupied by an indefinite article and adjective (a great). This suggests that the participants needed to process a larger segment of a sentence, thereby activating additional patterns rather than just resorting to the generalized schema of parallel structure.

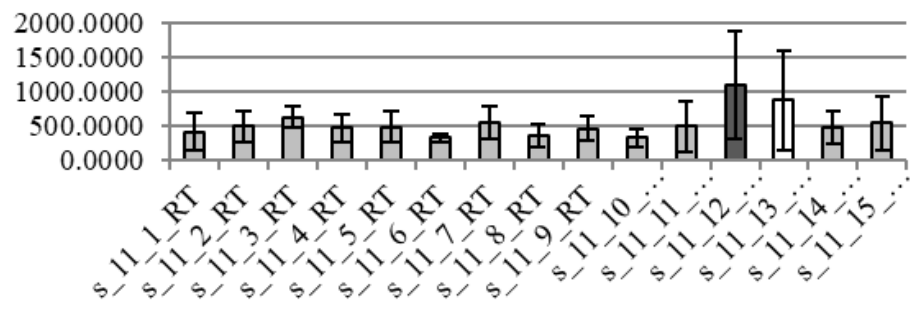

Fig. 32 RTs for Sentence 11 


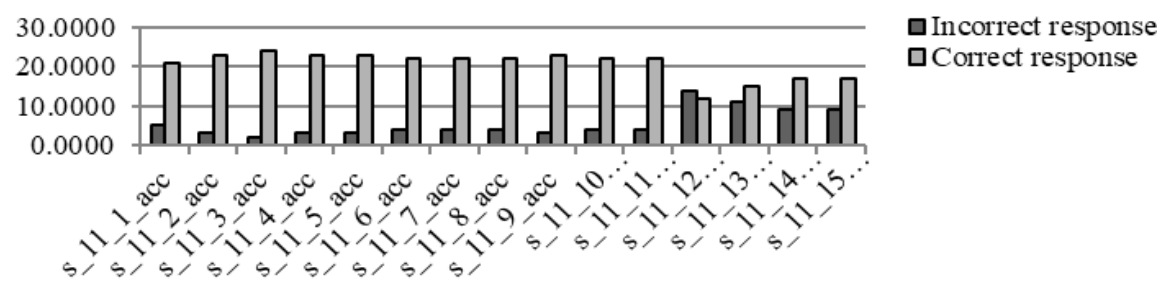

Fig. 33 Accuracy for Sentence 11

Accuracy analysis showed a sudden drop in the number of accurate responses in the error position, with a higher count of incorrect compared to correct responses (Figure 33). A similar trend continued until the end of the sentence, although with a somewhat higher count of correct responses. It can be seen that once again processing difficulties have led to a sudden decrease in the accuracy of participants' grammaticality judgments.

\subsubsection{Sentence 14}

Like in the previous sentence, the first part of parallel structure contains an entire verb phrase, while the second part contains a noun phrase (Not only is the house spacious but also *a large swimming pool). Figure 34 shows an increase in RT in the error position ( $9^{\text {th }}$ position), and an even greater lag in the subsequent position. Repeated measures ANOVA showed significant differences in RTs in the following cases: (i) $\mathrm{RT}_{9}$ and $\mathrm{RT}_{7}$ $\left(\mathrm{M}_{9}=1104.80 \mathrm{~ms}, \mathrm{SD}_{9}=644.53 \mathrm{~ms}, \mathrm{M}_{7}=455.60 \mathrm{~ms}, \mathrm{SD}_{7}=159.22 \mathrm{~ms}, \mathrm{p}=.016\right)$; (ii) $\mathrm{RT}_{9}$ and $\mathrm{RT}_{8}\left(\mathrm{M}_{9}=1104.80 \mathrm{~ms}, \mathrm{SD}_{9}=644.53 \mathrm{~ms}, \mathrm{M}_{8}=602.73 \mathrm{~ms}, \mathrm{SD}_{8}=517.03 \mathrm{~ms}, \mathrm{p}=.015\right)$; (iii) $\mathrm{RT}_{9}$ and $\mathrm{RT}_{11}\left(\mathrm{M}_{9}=1104.80 \mathrm{~ms}, \mathrm{SD}_{9}=644.53 \mathrm{~ms}, \mathrm{M}_{11}=592.87 \mathrm{~ms}, \mathrm{SD}_{11}=235.40 \mathrm{~ms}, \mathrm{p}=.005\right)$. Difference between $\mathrm{RT}_{9}$ and $\mathrm{RT}_{10}$ did not reach significance $(\mathrm{p}=.697)$. Like in the previous example, the identified spillover was obviously caused by the fact that the error and the subsequent position contain an indefinite article and adjective (a large), which again shows that participants did not only activate the generalized pattern of parallel structure, but that additional, more basic patterns were also active. In effect, it is such interplay of patterns and expectancies that seems to have caused the recorded spillover.

Analysis of accuracy again revealed a drop in the number of accurate responses associated with processing difficulties, and this tendency was preserved until the end of the sentence (Figure 35).

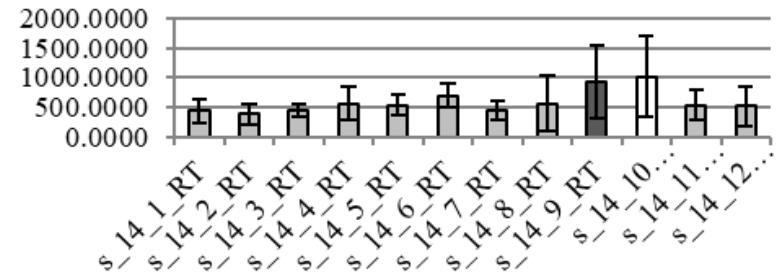

Fig. 34 RTs for Sentence 14 


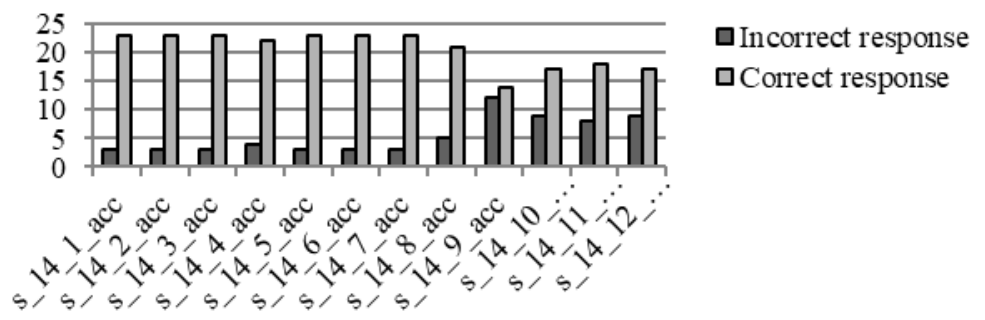

Fig. 35 Accuracy for Sentence 14

\section{DISCUSSION}

Analysis of RTs revealed processing difficulties in error positions in most of the sentences (with the exception of sentences 4 and 15), and in the majority of cases the lag in RT reached significance compared to the RTs in the adjacent sections of the sentence. Additionally, the increase in RT occurred precisely in the error position in all cases, with the exception of Sentences 9 and 14 where the lag occurred immediately after the error position. Such results suggest that the participants have acquired the abstract pattern of parallel structure from their L2, since the lag in RT was consistently linked to the violation of expectancies irrespective of the error type.

In turn, based on the obtained results presented above it can be concluded that the recorded lags in RTs, which occurred predominantly in error positions, can be associated with the violation of expectancies generated by the abstract generalized pattern of parallel structure. This result can be interpreted in two ways. Firstly, and more importantly, it shows that advanced EFL students have developed an abstract, generalized schema for parallel structure, which is reflected in increased processing times for parts of sentences containing faulty parallelism. Furthermore, the consistency of delays in RTs regardless of the specific type of the error (see sections 4.1 through 4.5 for details) suggests that this abstract schema of parallel structure is also psychologically real. Secondly, it can also be argued that the first segment of parallel structure provided online schematic priming for the second segment, and, in turn, the violation of the thereby generated expectancies led to processing difficulties reflected in increased RTs in error positions (in line with Frazier et al. 1984, and Branigan et al. 1995). The fact that in the majority of cases the lag in RTs occurred precisely in the error position further contributes to the idea that elements of a sentence are processed incrementally (in the sense of Pickering and van Gompel 2006). Additionally, the results are aligned with the findings obtained by Frazier et al. (1984) where the researchers also managed to identify an increase in reading times in cases where the coordinated parts of a sentence were not parallel in structure.

The analysis of accuracy showed that the lag in RT is typically associated with the sudden drop in the number of accurate responses, although the difference between accurate and inaccurate responses did not reach significance in most of the cases. These results suggest that, in the case of the present sample of participants, processing difficulties can be used to predict the accuracy of grammaticality judgments. One way to interpret this finding is that, although the increased RTs in error positions suggest that the abstract grammatical pattern of parallel structure is present, the sudden drop in the number of accurate responses suggests that the pattern has not yet been completely 
acquired. In plain terms, processing difficulties show that the participants are aware that there is something wrong with the sentence in the error position; however, they are still not able to judge the grammaticality of those parts of sentences with complete accuracy.

One additional factor that has obviously affected the level of recorded accuracy judgments is the error position and the type of error. Namely, in sentences of error type 1 (phrase vs. clause), the error was located in the sentence-final position, and the number of incorrect responses in the error position was consistently higher compared to accurate responses, reaching significance or marginal significance. In error type 2 sentences (-ing phrase vs. clause) this trend was preserved in Sentence 16, where the error was located in the sentence-final position. However, in Sentences 2 and 13, where the error was located in the second half of the sentence, the ratio of accurate/inaccurate responses was almost equal. In error type 3 sentences (-ing phrase vs. to-infinitive phrase), however, despite the decrease in accuracy, the number of accurate responses remained higher compared to inaccurate ones. In this case the error was located approximately at the onset of the second segment of parallel structure, immediately following the second part of the correlative conjunction. In error type 4 sentences (PP vs. NP) the error was again located in the sentence-final position; however, this did not affect accuracy ratings and the number of accurate responses remained higher compared to inaccurate ones, although it did not reach significance. This suggests that the violation of a prepositional phrase in parallel structure was much easier for participants to judge as incorrect. Finally, with error type 5 sentences (VP vs. NP), the error was located in the middle of the second part of a sentence and the difference in the number of correct and incorrect responses in the error position again is approximately the same in Sentence 11, while the number of accurate responses is higher in Sentence 14.

These results show that the participants were most successful in grammaticality judgments for sentences in which there were discrepancies (i) between -ing and -to infinitive verb phrases, (ii) between prepositional and noun phrases, and (iii) between verb an noun phrases. In cases with discrepancies between a clause and a phrase, and between an -ing phrase and a clause, the degree of accuracy in the error position rapidly decreased. In other words, participants were more accurate in grammaticality judgments in cases with simpler syntactic structures (discrepancies between phrases) than in cases with more complex structures (clause vs. phrase). This finding again suggests that even though a generalized pattern has been developed, a lower accuracy rate with more complex structures signals that it has not yet been fully acquired. This information is also useful for EFL teaching as it clearly and precisely uncovers the points of difficulties in grammatical processing for EFL students. The obtained results suggest that more attention should be paid to complex grammatical structures, since they caused the highest offset in accuracy of participants' grammatically judgments.

\section{CONCLUSIONS AND SUGGESTIONS FOR FUTURE RESEARCH}

The results obtained from the present study show that the English correlative conjunction not only ... but also indeed has a psychological reality for advanced Serbian EFL students. This is reflected in increased processing times for parts of sentences associated with the violation of expectancies generated by the abstract schema of parallel structure. Additionally, the identified reduction in the number of accurate responses associated with the error suggests that this pattern has not yet been completely acquired. 
The obtained results are valuable not only in the context of investigating the cognitive status of grammatical patterns, but also in the context of EFL teaching as they clearly point out the main difficulties in processing and comprehension.

Future research should address the level of acquisition of grammatical patterns with EFL students in more detail by connecting the experimental procedures to the dominant approaches in research on second language acquisition. Also, an online RT study should be coupled with an offline questionnaire-based grammaticality judgment study where participants would be given more time and be presented with the entire sentence context, which should in turn yield a higher rate of accuracy as it would eliminate the strain on working memory. Also, the research would benefit from a control group which would be exposed to accurate sentences, and the comparison of RTs and accuracy ratings in the accurate and inaccurate conditions should also afford a more thorough insight into online processing and activation of generalized schemas. Additionally, the study should be expanded in order to include more correlative conjunctions and explore whether their frequency in corpora functions as a confounding variable in relation to processing times and accuracy of grammaticality judgments. Further insight can also be obtained by replicating the experiment with native speakers of English.

\section{REFERENCES}

Biber, D., Johansson, S., Leech, G., Conrad, S., and Finegan, E., (1999), Longman Grammar of Spoken and Written English, Longman, Harlow.

Branigan, H.P., Pickering, M.J., Liversedge, S.P., Stewart, A.J., and Urbach, T.P, (1995), "Syntactic Priming: Investigating the Mental Representation of Language", Journal of Psycholinguistic Research 24, Vol. 6: pp. 489-506. https://doi.org/10.1007/BF02143163

Chomsky, N. (2002[1957]), Syntactic Structures, $2^{\text {nd }}$ edition, Mouton de Gruyter, Berlin and New York.

Chomsky, N. (1965), Aspects of the Theory of Syntax, The MIT Press, Cambridge, Massachusetts.

Frazier, L., Taft, L., Roeper, T., Clifton, C, and Ehrlich, K., (1984), "Parallel structure: A source of facilitation in sentence comprehension", Memory \& Cognition 12, Vol. 5: pp. 421-430. https://doi.org/10.3758/BF03198303

Greenbaum, S. and Quirk, R. (1990), A Student's Grammar of the English Language, Longman, London.

Greenbaum, S. and Nelson, G., (2002), An Introduction to English Grammar, $2^{\text {nd }}$ edition, Longman, London.

Jackedoff, R. (1994), Patterns in the Mind: Language and Human Nature, Basic Books, New York.

Just, M.A., Carpenter, P.A., and Woolley, J.D., (1982), "Paradigms and Processes in Reading Comprehension", Journal of Experimental Psychology: General 111, Vol. 2: pp. 228-238. http://dx.doi.org/10.1037/00963445.111.2.228

Kay, P. and Fillmore, C.J. (1999), “Grammatical Constructions and Linguistic Generalizations: The What's X Doing Y? Construction”, Language, Vol. 75, No. 1, pp. 1-33. doi: 10.2307/417472

Kong, L., Zhang, J.K., and Zhang, Y., (2016), "Are Chinese Correlative Conjunctions Psychologically Real? An Investigation of the Combination Frequency Effect”, Psychological Reports 0, Vol. 0: pp. 1-18. https://doi.org/10.1177/0033294116658631

Langacker, R.W. (1986), "An Introduction to Cognitive Grammar”, Cognitive Science, 10, pp. 1-40. https://doi.org/10.1207/s15516709 cog1001_1

Langacker, R.W. (1987), Foundations of Cognitive Grammar: Theoretical Prerequisites, Stanford University Press, Stanford, California.

Langacker, R.W. (1991), Foundations of Cognitive Grammar: Descriptive Application, Stanford University Press, Stanford, California.

Langacker, R.W., (2006), "Cognitive Grammar”, In: Geeraerts, D. (ed.) Cognitive Linguistics - Basic Readings: pp. 29-68, Mouton de Gruyter, Berlin and New York.

Langacker, R.W., (2008), Cognitive Grammar: A Basic Introduction. Oxford University Press, Oxford.

Lester, M., (2008), ESL Grammar: A Handbook for Intermediate and Advanced ESL Students, McGraw Hill, New York.

Mathôt, S., Schreij, D., and Theeuwes, J., (2012), "OpenSesame: An open-source, graphical experiment builder for the social sciences", Behavior Research Methods 44, Vol. 2: pp. 314-324. https://doi.org/10.3758/s13428-0110168-7 
Pickering, M. and van Gompel, R.P.G., (2006), "Syntactic Parsing”, In: Traxler, M.J. and M.A. Gernsbacher (eds.) Handbook of Psycholinguistics, $2^{\text {nd }}$ edition: pp. 455-503, Elsevier, London.

Pollock, C.W., (1982), Communicate What You Mean, Prentice-Hall Inc., New Jersey.

Quirk, R., Greenbaum, S., Leech, G., and Svartvik, J., (1985), A Comprehensive Grammar of the English Language, Longman, London and New York.

\section{ISPITIVANJE PSIHOLOŠKE REALNOSTI \\ PARALELNIH STRUKTURA NA UZORKU SRPSKIH STUDENATA ENGLESKOG JEZIKA: STUDIJA SLUČAJA SA „NOT ONLY ... BUT ALSO“}

Cilj rada je da ispitamo kognitivni status veznika „,not only ... but also “ na uzorku srpskih studenata engleskog jezika na naprednom nivou. Eksperimentalna procedura uključuje ocene gramatičnosti $i$ koristi merenje vremena reakcije posredstvom paradigme "pokretnih ekrana". Draži (rečenice) sastavljene su na osnovu najčešćih grešaka koje studenti prave na ispitima. Rečenice sa greškama prezentovane su reč-po-reč, sa maskom, uz pomoć softverskog paketa Open Sesame. Duže vreme reakcije tumači se kao znak teškoća u obradi, a pored vremena reakcije, merena je i tačnost odgovora. Dobijeni rezultati pokazuju da se u većini slučajeva "kašnjenje" javilo tačno gde i greška, što je takođe bilo praćeno i naglim smanjenjem broja tačnih odgovora.

Ključne reči: paralelne strukture, ocene gramatičnosti, vreme reakcije, psiholingvistika, Open Sesame, engleski jezik kao strani 